\section{TEXT-BOOK OF SPECTROCHEMICAL ANALYSIS}

Principles and Practice of Spectrochemical Analysis By Prof. Norman H. Nachtrieb. Pp. $\mathrm{x}+324$. (London: McGraw-Hill Publishing Co., Ltd., 1950.) 38s. $6 d$.

THE most rapid strides in the application of spectrographic methods to chemical analysis have taken place between 1930 and the end of the Second World War, and it has been noticeable that the production of good text-books on the subject has lagged behind this development to a considerable extent. The well-known and almost classical work of Brode has stood nearly alone for many years; recently, however, quite a number of authors have taken steps to remedy this deficiency. This work of Prof. N. H. Nachtrieb follows several recently published books on the subject and, of necessity, there must be some duplication of information in books dealing with different aspects of the same topic.

Prof. Nachtrieb has divided his treatment of the subject into two parts : "Principles", namely, theory and instrumentation, and "Practice", applications and technique. To deal with the subject-matter in this order, it can be stated that he has given a very full and comprehensive survey of the theory of the production and interpretation of spectra and the underlying fundamentals of the apparatus that is used for their recording; it is amply adequate for those for whom the book is intended, namely, analytical chemists. There may be some who would contend that it is even too comprehensive in this respect; for example, the theory of the photographic process could be considered ancillary to spectrographic procedure. Nevertheless, in a chapter on this topic the author emphasizes the value of photographic recording in providing a permanent record.

The instrumentation also receives extensive study, although, perhaps, the quantometer deserves a rather fuller description than it has received. A notable omission here, however, is the failure to describe any of the excellent and well-tried excitation sources that have been devised and are in use both in Great Britain and on the Continent of Europe. The name of Pfeilsticker, for example, who could be called the 'father' of controlled circuits, has not even been mentioned.

After a lucid exposition of the principles of spectrochemical analysis of such excellent quality, which occupies more than two hundred pages of the book, the hundred pages of practice come somewhat as an anticlimax. Prof. Nachtrieb has explained that it would be impossible to describe every technique, but he has confined himself far too much to American practice almost to the exclusion of methods from British and European laboratories. One exception is the Lundegårdh technique, but in his treatment of this method he has included details which have been out of date for some time, while omitting or only briefly noting more important matter. It is understandable perhaps that Prof. Nachtrieb's copperspark method receives a detailed description, but other methods of performing similar operations should at least have received mention. It is very pleasing to see a final chapter on chemical preparation prior to a spectrographic finish; this chapter should receive the attention, in particular, of those who are in operational control of general analytical laboratories in which spectrographic methods are used.
A rather restricted bibliography is unfortunate, but is consequent upon the somewhat limited scope of the author's references to methods and techniques.

In general, this work has been written in a most readable style, though anyone not familiar with American idiom will need to read warily : for example, "in case" usually means "lest" in English, but it is used to mean "when" in this text; also "sawed" instead of "sawn" is harsh on British ears. There can be no criticism whatever of lack of diagrams and illustrations with which the book is copiously supplied, and which are all well executed. No more need be said of the binding, printing and quality of this book than that it is of the high standard that has come to be expected of the scientific literature of the United States.

In conclusion, this work should undoubtedly find a place in scientific libraries, if only for its excellent treatment of the theory of spectrochemical analysis in so far as it is needed by analytical chemists; but the somewhat limited scope of the practical side will exclude it from the category of a handbook for all spectrographers. J. A. C. McClelland

\section{THE VITAMINS}

\section{Vitamins}

A Digest of Current Knowledge. By Dr. Leslie J. Harris. Pp. xii + 244. (London: J. and A. Churchill, Ltd., 1951.) 15s, net.

TUTRITION, a relatively new science, necessarily D rests on several of the older sciences such as chemistry, biochemistry, physiology and clinical medicine. The writer of a text-book in the field of nutrition always therefore faces the difficulty that his readers are likely to have experience in only one or two of these basic sciences. Dr. Leslie Harris addresses himself in this book to students and graduates in biochemistry, chemistry, pathology, dietetics and medicine. The failure of most books on nutrition to meet anything like these requirements makes a reviewer more than a little sceptical of an author's ability to justify such claims.

It can, however, be said at once that Dr. Harris succeeds brilliantly. In a book of just over two hundred small pages he has managed to give a clear outline of every aspect of the vitamins. The biochemist will find a concise and accurate description of reactions in which many of the vitamins are involved, reactions which he will often not find so well summarized elsewhere. At the same-time, he will be able to follow with ease the clinical aspects of vitamin deficiency disease and will be especially helped by the admirable glossary of medical terms and the profuse illustrations of deficiency-states in animals and man. Similarly, those with little chemical training should have no difficulty in understanding the formulæ and equations liberally distributed through the book. Again, the research worker will be able to view his problems in true perspective and will be guided through the literature by the extensive and up-to-date lists of general and special references.

In recommending this book without hesitation to all who require a summary of the present knowledge of the vitamins, one must congratulate Dr. Harris on presenting such a readable, concise, accurate and well-documented account for such a wide variety of readers.
JOHN YUDKIN 